\title{
The effect of an incremental increase in exercise on appetite, eating behaviour and energy balance in lean men and women feeding ad libitum
}

\author{
Stephen Whybrow ${ }^{1}$, Darren A. Hughes ${ }^{1}$, Patrick Ritz ${ }^{2}$, Alexandra M. Johnstone ${ }^{1}$, Graham W. Horgan ${ }^{3}$, \\ Neil King ${ }^{4}$, John E. Blundell ${ }^{4}$ and R. James Stubbs ${ }^{5}$ \\ ${ }^{1}$ The Rowett Research Institute, Greenburn Road, Aberdeen AB21 9SB, UK \\ ${ }^{2}$ Service de Medecine, Chu-49033, Angers, Cedex 01, France \\ ${ }^{3}$ Biomathematics and Statistics, Scotland, The Rowett Research Institute, Greenburn Road, Aberdeen AB21 9SB, UK \\ ${ }^{4}$ BioPsychology Group, Institute of Psychological Sciences, University of Leeds, Leeds LS2 9JT, UK \\ ${ }^{5}$ Slimming World, Clover Nook Road, Somercotes, Alfreton, Derbyshire DE55 4RF, UK
}

(Received 18 February 2007 - Revised 10 January 2008 - Accepted 25 February 2008 - First published online 1 April 2008)

The effects of incremental exercise on appetite, energy intake (EI), expenditure (EE) and balance (EB) in lean men and women were examined. Six men (age 29.7 (SD 5.9) years, weight 75.2 (SD 15.3) kg, height 1.75 (SD 0.11) m) and six women (age 24.7 (SD 5.9) years, weight 66.7 (SD 9.10 ) $\mathrm{kg}$, height $1.70(\mathrm{SD} 0.09) \mathrm{m}$ ) were each studied three times during a $16 \mathrm{~d}$ protocol, corresponding to no additional exercise (Nex), moderate-intensity exercise (Mex; 1.5-2.0 MJ/d) and high-intensity exercise (Hex; 3.0-4.0 MJ/d) regimens. Subjects were fed to EB during days 1-2, and during days 3-16 they fed ad libitum from a medium-fat diet of constant composition. Daily EE, assessed using the doubly labelled water method, was 9.2, 11.6 and $13.7 \mathrm{MJ} / \mathrm{d}(P<0.001$; SED 0.45$)$ for the women and $12.2,14.0$ and $16.7 \mathrm{MJ} / \mathrm{d}(P=0.007$; SED 1.11$)$ for the men on the Nex, Mex and Hex treatments, respectively. EI was $8.3,8.6$ and $9.9 \mathrm{MJ} / \mathrm{d}(P=0.118$; SED 0.72$)$ for the women and $10.6,11.6$ and $12.0 \mathrm{MJ} / \mathrm{d}$ $(P=0.031$; SED 0.47$)$ for the men, respectively. On average, subjects compensated for about $30 \%$ of the exercise-induced energy deficit. However, the degree of compensation varied considerably among individuals. The present study captured the initial compensation in EI for exercise-induced energy deficits. Total compensation would take a matter of weeks.

Exercise: Appetite: Energy balance: Feeding behaviour: Human studies

A low level of physical activity, typical of Western society, is deemed conducive to weight gain ${ }^{(1,2)}$. In addition, it is believed by some that increases in physical activity will promote weight loss ${ }^{(3)}$. However, individuals are unlikely to continue to lose weight over prolonged periods if they elevate daily energy expenditure (EE) by increasing physical activity (for example, Sum et al. ${ }^{(4)}$ ). It is intuitively obvious that energy intake (EI) will eventually begin to track EE, and body weight will stabilise. However, the exact manner in which changes in levels of physical activity influence feeding behaviour over periods long enough to affect energy balance (EB) is not clearly understood. There is a large body of literature on the effect of training programmes on body weight and composition in athletes ${ }^{(5-10)}$. Likewise, a number of important studies have examined the effects of training programmes on weight loss in obese subjects (for example, Schoeller et al. ${ }^{(11)}$ and Saris $\left.{ }^{(12)}\right)$. Fewer studies have examined the relationship between changes in EE and feeding behaviour in normally sedentary, non-obese subjects who do not have a pre-conceived goal of weight reduction or a training programme. The reviews of King et al. of the effects of exercise regimens on appetite and EI show that in short- to mediumterm intervention studies (often no longer than 2-5d), $19 \%$ report an increase in EI after exercise; $65 \%$ show no change and $16 \%$ show a decrease ${ }^{(13-15)}$. Longer-term studies that measure body composition suggest some fat mass is lost but lean body mass tends to be preserved in response to exercise regimens, depending on the absolute level of $\mathrm{EB}^{(4,16)}$. There are fewer data in the literature on how changes in EI respond to alterations in EE over periods of 1-2 weeks.

With the above considerations in mind, the present study was designed as one of a series using methodologies that allow comparison with previous studies ${ }^{(6,17-27)}$. In two previous studies we found that women compensated their EI over $7 \mathrm{~d}$ by $25-30 \%$ for about zero, 1.5 and $3.0 \mathrm{MJ} / \mathrm{d}$ of mandatory, exercise-induced $\mathrm{EE}^{(26)}$ but men did not ${ }^{(27)}$. The present study extended these protocols, using the same exercise prescription, to a $14 \mathrm{~d}$ exercise intervention in men and women. EB was assessed with greater precision; total daily EE was estimated using doubly labelled water (instead of heart rate monitoring as in our previous studies), and EI was quantified by providing subjects with a diet of constant measurable composition as used in previous

Abbreviations: EB, energy balance; EE, energy expenditure; EI, energy intake; Hex, high-intensity exercise; HRM, heart rate monitor; Mex, moderate-intensity exercise; Nex, no additional exercise.

* Corresponding author: Dr S. Whybrow, fax +44 1224 715349, email S.Whybrow@Rowett.ac.uk 
feeding behaviour studies ${ }^{(28,29)}$. The present study was designed to continually monitor these variables, together with subjective appetite, in the same relatively sedentary men and women exposed to no, moderate or high levels of exercise-induced EE under 'pseudo free-living' conditions.

\section{Materials and methods}

\section{Subject recruitment}

Six men and six women were recruited by advertisement. Subjects were non-smokers, aged between 18 and 40 years, in good health (no chronic health complaints, not taking any medication, with the exception of oral contraceptives in women), not consuming any type of specialised diet, had a sedentary to moderately active lifestyle and were not highly restrained eaters. They were not informed that the true purpose of the study was to specifically assess feeding responses to physical activity. Instead, emphasis was placed on $\mathrm{N}$ excretion and metabolism. Subjects were asked not to monitor their weight during the course of the study. All subjects were interviewed and informed of procedures involved in the study before signing a consent form. The study was approved by the Grampian Health Ethics Committee.

\section{Experimental design}

Each subject was studied three times, using a randomised cross-over design, with no additional exercise (Nex), moderate exercise (Mex) and high exercise (Hex) treatment periods. Each experimental treatment period lasted $16 \mathrm{~d}$, during which time they were resident in, but not confined to, the Human Nutrition Unit of the Rowett Research Institute. They were allowed to come and go from the unit to maintain their usual day-to-day activities. During days 1-2, subjects were fed a maintenance diet. They took part in the exercise intervention during days 3-16. Treatment order was randomised and balanced across subjects. The three treatments were: (i) Nex, where subjects were asked to maintain their usual activity routines (control); (ii) Mex, in which subjects completed two $40 \mathrm{~min}$ sessions per d in order to expend $28.6 \mathrm{~kJ} / \mathrm{kg}$ body weight (giving $2.0 \mathrm{MJ} / \mathrm{d}$ for a $70 \mathrm{~kg}$ subject); (iii) Hex, during which subjects completed three $40 \mathrm{~min}$ sessions per $\mathrm{d}$ in order to expend $57.1 \mathrm{~kJ} / \mathrm{kg}$ body weight (giving $4.0 \mathrm{MJ} / \mathrm{d}$ for a $70 \mathrm{~kg}$ subject). Subjects exercised primarily on a bicycle ergometer (Tunturi E850; Tunturi, Turku, Finland) although some subjects used a treadmill (Powerjog G100; Sports Engineering Ltd, Bryncoch, Mid Glamorgan, UK). Each study period was separated by at least 1 week, although this varied considerably between subjects.

The intensity at which subjects exercised was estimated individually by means of a submaximal fitness test and was scaled to the individual's body weight. This test was used to individually calibrate heart rate monitors (HRM; POLAR sports tester; Polar Electro, Vantaa, Finland). The HRM were used to measure the energy cost of exercise during each exercise session, using the modified heart rate flex (HR-FLEX) method ${ }^{(30)}$. Subjects only wore the HRM during exercise sessions to check compliance to the protocol. Average total daily EE was measured in each subject using the doubly labelled water method (see below).
The purpose of the maintenance diet on days 1-2 was to standardise energy and macronutrient intakes before each exercise intervention. The energy content of the diet was calculated at $1.6 \times$ RMR and provided $13 \%$ protein, $40 \%$ fat and $47 \%$ carbohydrate. From days $3-16$, subjects were given continuous ad libitum access to a $3 \mathrm{~d}$ rotating menu of a similar composition and energy density (see below). Subjects also had ad libitum access to water, decaffeinated tea, fruit squash or coffee with a non-nutritive sweetener $\left(\right.$ Canderel $^{\mathrm{TM}}$; Merisant UK Ltd, High Wycombe, Bucks, UK) and were given a $200 \mathrm{~g}$ semi-skimmed milk allowance per d. They were not allowed to drink any alcohol during the whole period. These diets have been described previously ${ }^{(28,29)}$.

Subjects recorded their motivation to eat during waking hours (days 1-16; see below).

At the beginning of the study, subjects completed the three factor eating inventory (TFEI) $)^{(31)}$ and the Dutch eating behaviour questionnaire (DEBQ) ${ }^{(32)}$. The DEBQ and TFEI showed that women's restraint was, on average, 2.9 (SD 0.6) and 7.0 (SD 4.0), respectively. Corresponding values for the men were 2.5 (SD 1.07) and 8.3 (SD 5.2). Neither group of men or women was classified as restrained eaters. It was not practicable to standardise the exercise treatments with reference to the menstrual cycle.

\section{Measurement of baseline anthropometry and resting metabolic rate}

Height and weight were measured as previously described ${ }^{(26)}$. $\mathrm{O}_{2}$ consumption and $\mathrm{CO}_{2}$ production were measured using a ventilated hood system (Deltatrac II, MBM-200; Datex Instrumentarium Corporation, Helsinki, Finland) in fasting subjects during the morning. Subjects rested for at least $30 \mathrm{~min}$ after arriving at the Human Nutrition Unit of the Rowett Research Institute, and measurements were made at approximate thermoneutrality. RMR was calculated using the equations of Elia \& Livesey ${ }^{(33)}$. Skinfold thickness was measured on the right-hand side of the body, using skinfold callipers (Holtain Ltd, Crymych, Dyfed, UK), following the methods of Durnin \& Womersley ${ }^{(34)}$, and percentage body fat estimated using the Siri equation ${ }^{(35)}$.

\section{Formulation and preparation of the diets}

The composition of each dish in terms of energy, fat, carbohydrate, protein and NSP was calculated from McCance and Widdowson's The Composition of Foods, 5th edition and supplements ${ }^{(36)}$. The ad libitum diet was formulated so that every food item on the menu comprised $40 \%$ fat, $47 \%$ carbohydrate and $13 \%$ protein as a proportion of energy and contained $550 \mathrm{~kJ} / 100 \mathrm{~g}$ wet weight of food (excluding drinks). This was done so that food intake directly paralleled EI. The food was prepared daily by the dietetic research assistant in the metabolic kitchen.

\section{Presentation of the diets and measurement of food intake}

Subjects were resident in the Human Nutrition Unit of the Rowett Research Institute for the duration of the study. Foods from the menu were available in excess from a labelled refrigerator and freezer. Food was presented to the subjects in the 
following amounts: breakfast, $600 \mathrm{~g}$; main courses, $400 \mathrm{~g}$; sweets, $150 \mathrm{~g}$; milkshakes, $300 \mathrm{~g}$; hot drinks, $350 \mathrm{~g}$. Extra portions were readily available on request. Foods were prepared in large batches and frozen in $400 \mathrm{~g}$ portions. Water loss from cooking was measured and replaced to maintain the calculated energy density. All foods were weighed before they were made available to subjects. Subjects would heat their own meals using a microwave oven. Empty containers and leftovers were placed back into the refrigerator for weighing and recording by the investigators so that food intake could be measured. Subjects also kept a food diary during the study period, in which they recorded food consumed and the times at which it was eaten. Subjects could, therefore, determine the time, size, and frequency but not the composition of each meal.

\section{Doubly labelled water technique}

Subjects were dosed with doubly labelled water on the morning of day 3. A pre-dose urine sample along with two further background samples collected on the maintenance days were used for assessment of baseline (pre-dose) isotopic enrichments of the subject's body water pools. The dose levels were: $0 \cdot 15 \mathrm{~g} / \mathrm{kg}$ body weight of a $99.9 \%{ }^{2} \mathrm{H}_{2} \mathrm{O}-\mathrm{H}_{2} \mathrm{O}$ mixture and $1.5 \mathrm{~g} / \mathrm{kg}$ body weight of a $10.0 \% \mathrm{H}_{2}{ }^{18} \mathrm{O}-\mathrm{H}_{2} \mathrm{O}$ mixture. This was made up as a single dose that was sealed and autoclaved the day before dosing. Subjects then collected urine samples at 4,5 and $6 \mathrm{~h}$ after dosing to enable plateaus to be individually measured using the 'slope intercept' method ${ }^{(37)}$. During days 4-16 inclusive, subjects continued to collect urine samples, which were immediately frozen at $-20^{\circ} \mathrm{C}$. Samples were collected at the same time each day and the exact time of collection was recorded. Urine samples were collected for a multi-point analysis.

Stable-isotope analysis was conducted using gas isotope ratio MS. Isotopic enrichment of the post-dose urine samples was analysed, relative to the original background amounts. However, in the present study the times of the doses were so close together, the true background was never reached after the first dose. Therefore to calculate pool sizes and flux rates, the original background was used. Pool sizes and flux rates were calculated as described by Coward ${ }^{(38)}$.

\section{Calibration of heart rate monitors and estimation of energy expenditure from heart rate}

Total exercise EE from HR was calculated using the modified heart rate flex (HR-FLEX) method of Ceesay et al. ${ }^{(30)}$, as described previously ${ }^{(27)}$. Submaximal calibration procedures were conducted before each treatment period on the same morning as the RMR measurement. A regression line of HR $v$. EE was established for each subject by simultaneously measuring HR, breath-by-breath $\mathrm{V}_{\mathrm{O} 2}$ and $\mathrm{V}_{\mathrm{CO} 2}$ (Vmax29 metabolic cart; Sensor Medics, Yorba Linda, CA, USA) at incremental workloads on a bicycle ergometer (Tunturi E850). EE was estimated from $\mathrm{V}_{\mathrm{O} 2}$ and $\mathrm{V}_{\mathrm{CO} 2}$ values ${ }^{(33,39)}$, and the individual relationships between HR and EE established. Subjects wore HRM during exercise sessions and the energy cost of each exercise session was estimated from the recording of heart rate.

Data derived from the calibration procedure were also used to predict each subject's maximum $\mathrm{O}_{2}$ uptake (predicted $\left.\mathrm{V}_{\mathrm{O} 2 \max }\right)$, by extrapolation of the regression of $\mathrm{V}_{\mathrm{O} 2}$ against
HR to the subject's calculated maximum heart rate of $220-$ age. The $\mathrm{V}_{\mathrm{O} 2}$ which coincides with maximal $\mathrm{HR}$ was assumed to be the maximum $\mathrm{O}_{2}$ uptake $\left(\mathrm{V}_{\mathrm{O} 2 \max }\right)$ and was expressed in $\mathrm{ml}$ per min and $\mathrm{kg}$ body weight ${ }^{(40)}$.

\section{Psychometric assessment of hunger and appetite}

Throughout each measurement day (between 09.00 and 21.00 hours) subjects rated hourly motivation to eat and mood using an electronic appetite rating system, based on visual analogue scales as described previously ${ }^{(26)}$.

\section{Statistical analysis}

$\mathrm{EE}$ and heart rate were analysed by ANOVA with exercise treatment and day as factors and subject and treatment order as blocking factors. In addition, pre- and post-treatment RMR was analysed by ANOVA with exercise treatment as a factor and subject and treatment order as blocking factors. Males and females were analysed separately, and in combination by including a term for sex in the between-subject stratum of ANOVA of the combined data.

Food, energy and nutrient intake were analysed by ANOVA with exercise treatment and day as factors and subject and treatment order as blocking factors. Additionally, period was added as an input factor to assess for changes between the treatment and follow-up phases of the protocol.

EB was analysed by ANOVA with exercise treatment and day as factors and subject and treatment order as blocking factors. Changes in body weight from day 3 to day 17 were analysed by ANOVA to test for treatment effects. For each treatment, $t$ tests were used to test for significant changes in weight (relative to zero) over the period.

Changes in EI, expenditure and balance were also summarised by simple linear regression calculating the slope, $P$ value and $t$ value, over time (d), as men and women separately and combined. This process necessarily assumed that total daily EE was constant on a daily basis, since the doubly labelled water technique provides only an average daily value from the $14 \mathrm{~d}$ measurement period.

The hourly visual analogue ratings were analysed using ANOVA by calculating a mean rating for each $24 \mathrm{~h}$ period with diet and day as a factor and subject and treatment order as a blocking factor.

All analysis was performed using the GENSTAT 5 statistical program (Lawes Agricultural Trust, Rothampstead Experimental Station, Harpenden, Herts, UK).

\section{Results}

Subject characteristics, as measured at baseline, are presented in Table 1.

\section{Energy balance}

Average daily EE (estimated using doubly labelled water) increased across treatments for both the women $(P<0001)$ and men $(P=0.001)$. For women the mean energy cost of exercise (inclusive of basal expenditure, as assessed by HRM) was 2.0 and $3.8 \mathrm{MJ} / \mathrm{d}$ on the Mex and Hex treatments respectively; for men it was 2.8 and $4.9 \mathrm{MJ} / \mathrm{d}$, respectively. 
Table 1. Subject characteristics at baseline

(Mean values and standard deviations)

\begin{tabular}{lccccc}
\hline & \multicolumn{2}{c}{ Women $(n 6)$} & & \multicolumn{2}{c}{ Men $(n 6)$} \\
\cline { 2 - 3 } \cline { 6 - 6 } & Mean & SD & & Mean & SD \\
\hline Age (years) & 24.7 & 5.9 & & 29.7 & 5.9 \\
Height $(\mathrm{m})$ & 1.70 & 0.09 & & 1.75 & 0.11 \\
Weight $(\mathrm{kg})$ & 66.7 & 9.10 & & 75.2 & 15.3 \\
BMl $\left(\mathrm{kg} / \mathrm{m}^{2}\right)$ & 22.9 & 1.6 & & 24.2 & 2.2 \\
Body fat $(\%)$ & 29.9 & 1.7 & & 19.3 & 4.4 \\
RMR (MJ/d) & 6.05 & 0.56 & & 7.03 & 1.3 \\
\hline
\end{tabular}

Mean heart rate, averaged over all exercise sessions, was significantly elevated by the exercise treatments, giving values of 136 and 149 beats per $\min$ for the women $(P=0.015$; SED 3.8) and 126 and 141 beats per min for the men, on the Mex and Hex treatments respectively $(P=0.004$; SED 3.0).

Table 2 summarises mean daily food, energy and macronutrient intakes, EE and RMR, and EB for the six men and women on each treatment, for days 3-16. Non-exercise EE (calculated from total EE - exercise EE) was not affected by the exercise intervention (Table 2); consequently total daily EE, both absolute and as a multiple of RMR, increased with increasing exercise.

There was no significant treatment effect on RMR, nor any difference within each treatment between days 3 and 16, either expressed in absolute terms $(\mathrm{kJ} / \mathrm{d})$ or as a proportion of fat-free mass $(\mathrm{kJ} / \mathrm{kg}$ fat-free mass per $\mathrm{d})$.

Average daily EI did not change significantly as exercise increased in the women $(P=0.118)$ but it did in the men $(P=0.031$; SED 0.47).

EI, regressed over the $14 \mathrm{~d}$ of each exercise treatment for men (Fig. 1 (a)) and women (Fig. 1 (b)) separately or combined, showed no evidence of a change over time. Mean slopes (combined across sexes) were $-0.07 \quad(t=-2.18$; $P=0.08), \quad-0.06(t=-0.64 ; P=0.55)$ and $0.05(t=0.83$; $P=0.44)$ on the Nex, Mex and Hex treatments, respectively.

Macronutrient intakes followed a similar non-significant pattern to EI for the women and a similar significant trend in the men, since the diets were of a fixed composition.
Mean daily EB, measured from EI minus EE, was significantly affected by treatment. Since intake did not change over time (see above) and expenditure was averaged over $14 \mathrm{~d}$ there were no treatment-day effects on EB. Cumulative EB was, on average $-12.6,-42.0$ and $-53.2 \mathrm{MJ}$ (SED 19.3) for the women and $-22.4,-33.6$ and $-65.8 \mathrm{MJ}$ (SED 13.2) for the men, on the Nex, Mex and Hex treatments respectively. There were no sex $\times$ treatment interactions. Cumulative EB was significantly different from zero on the Hex treatments for the women $(P=0.007 ; t=-4.34)$ and men $(P=0.023 ; t=3.23)$; in addition the women's Mex treatment was significantly different from zero $(-42.0 \mathrm{MJ}$; $P=0.014 ; t=-3 \cdot 68)$. EB was not significantly different from zero on the Nex treatment for either women or men.

\section{Body weight}

There were no significant differences in body weight (day 17 minus day 3) between the Nex, Mex and Hex treatments of the study. None of the changes in body weight were significantly different from zero.

\section{Aerobic fitness}

There was a significant treatment effect on predicted $\mathrm{V}_{\mathrm{O} 2 \max }$ $(\mathrm{ml} \mathrm{O} / 2 \mathrm{~kg}$ per $\mathrm{min})$ in the women $(P=0.029$; SED 2.6). Predicted maximal aerobic power increased from 30.00 (Nex) to $38.67 \mathrm{ml} \mathrm{O}_{2} / \mathrm{kg}$ per min on the Hex treatment. For the men the increase was not significant, going from 40.70 to $46.56(P=0.072)$.

\section{Body composition}

There was no significant change in fat-free mass, fat mass or percentage body fat across the three treatments for the women or the men.

\section{Motivation to eat and mood}

There were no significant treatment effects for hunger, fullness, desire to eat, prospective consumption, thirst or preoccupation with thoughts of food for the women. Similarly, the men only rated thirst as being significantly elevated during the Mex treatment $(P=0.017$; SED 4$)$, with average scores of 30,43 and 37 on the Nex, Mex and Hex treatments respectively.

Table 2. Mean daily energy intake, expenditure, and their components together with energy balance for women and men during the intervention period of three separate treatments: no exercise (Nex), moderate level of exercise (Mex) and high level of exercise $(\mathrm{Hex})^{\star}$

(Mean values and standard errors of difference)

\begin{tabular}{|c|c|c|c|c|c|c|c|c|c|c|}
\hline & \multicolumn{5}{|c|}{ Women $(n 6)$} & \multicolumn{5}{|c|}{$\operatorname{Men}(n 6)$} \\
\hline & $\mathrm{Nex}$ & Mex & Hex & SED & $P$ & Nex & Mex & Hex & SED & $P$ \\
\hline Total daily energy expenditure (MJ/d) & $9 \cdot 2$ & 11.6 & 13.7 & 0.45 & $<0.001$ & $12 \cdot 2$ & 14.0 & $16 \cdot 7$ & $1 \cdot 1$ & 0.007 \\
\hline Exercise energy expenditure $(\mathrm{MJ} / \mathrm{d})$ & About 0.3 & $2 \cdot 0$ & 3.8 & 0.16 & $<0.001$ & About 0.5 & $2 \cdot 8$ & 4.9 & 0.16 & $<0.001$ \\
\hline RMR (MJ/d) & 6.1 & $6 \cdot 1$ & 5.9 & 0.48 & 0.634 & 7.0 & $7 \cdot 2$ & $6 \cdot 9$ & 0.14 & 0.239 \\
\hline Food and drink eaten $(\mathrm{kg} / \mathrm{d})$ & $2 \cdot 10$ & $2 \cdot 29$ & 2.83 & 0.24 & 0.029 & 3.3 & 3.7 & 4.0 & 0.19 & 0.016 \\
\hline Energy intake $(\mathrm{MJ} / \mathrm{d})$ & $8 \cdot 3$ & 8.6 & 9.9 & 0.72 & $0 \cdot 118$ & $10 \cdot 6$ & 11.6 & $12 \cdot 0$ & 0.47 & 0.031 \\
\hline Protein intake $(\mathrm{MJ} / \mathrm{d})$ & 1.1 & $1 \cdot 1$ & 1.3 & 0.10 & 0.170 & 1.4 & 1.5 & 1.5 & 0.07 & 0.054 \\
\hline Carbohydrate intake (MJ/d) & $4 \cdot 1$ & 4.3 & $5 \cdot 0$ & 0.34 & 0.074 & $5 \cdot 2$ & $5 \cdot 7$ & 5.9 & 0.23 & 0.026 \\
\hline Fat intake $(\mathrm{MJ} / \mathrm{d})$ & 3.1 & $3 \cdot 2$ & 3.7 & 0.29 & 0.184 & 4.0 & 4.4 & 4.6 & 0.18 & 0.043 \\
\hline Energy balance $(\mathrm{MJ} / \mathrm{d})$ & -0.9 & $-3 \cdot 0$ & -3.8 & 0.90 & 0.022 & $-1 \cdot 6$ & $-2 \cdot 4$ & -4.7 & 0.98 & 0.025 \\
\hline Weight change $(\mathrm{kg} / 14 \mathrm{~d})$ & -0.98 & -0.67 & -0.63 & 0.28 & 0.725 & -0.20 & -0.96 & $-1 \cdot 13$ & 0.69 & 0.213 \\
\hline
\end{tabular}

*Note that weight of food and drink includes non-energy drinks such as water and beverages such as tea. 

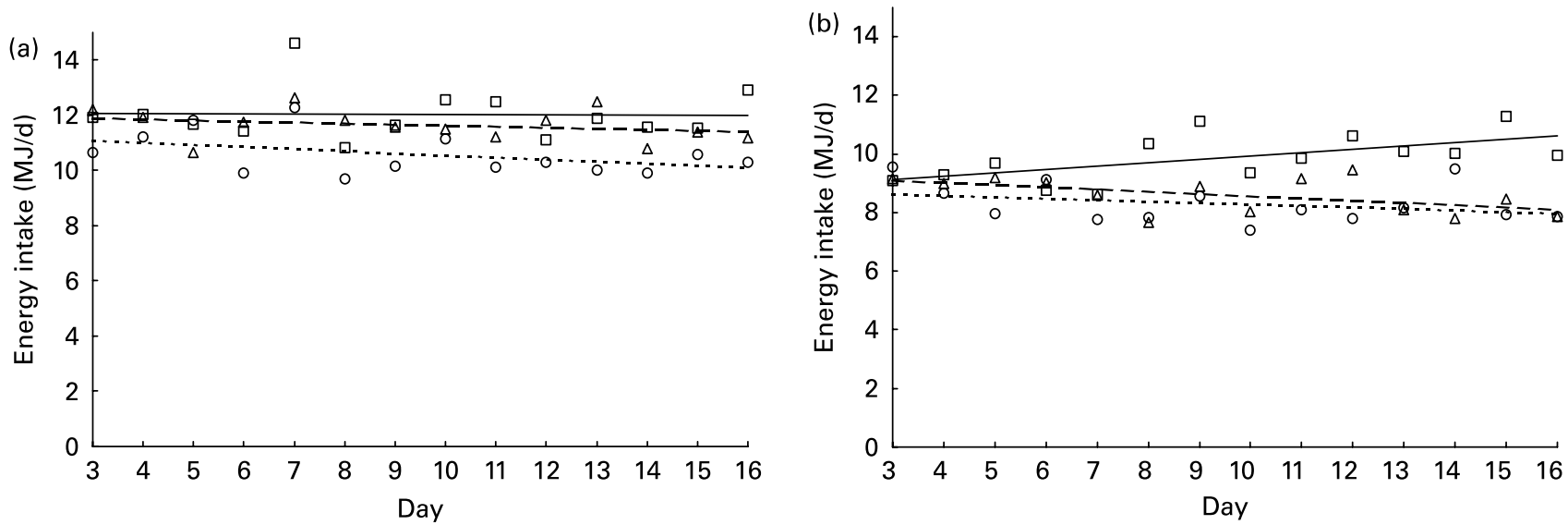

Fig. 1. Regression of daily energy intakes and study day for men (a) and women (b) for each treatment: no additional exercise (O; ---), moderate level of exercise $(\triangle ;---)$ and high level of exercise $(\square ;-)$.

\section{Discussion}

The effect of the exercise intervention on total daily energy expenditure

As in our two previous $7 \mathrm{~d}$ studies, a graded increase in exercise EE markedly elevated total daily EE, resulting in a negative EB, which was roughly proportional to the energy cost of exercise. Subjects in our previous studies tended to expend more than the required prescription at the outset of the study, and daily EE declined during the course of the study by about $0 \cdot 3-0 \cdot 6 \mathrm{MJ} / \mathrm{d}$ on the Hex regimen and $0 \cdot 3-0.4 \mathrm{MJ} / \mathrm{d}$ on the Mex regimen ${ }^{(26,27)}$. It was not possible to ascertain whether this occurred in the present study since daily EE was measured as an average per subject over each $14 \mathrm{~d}$ treatment period. With this caveat in mind, there was little evidence that sustained increases in EE through exercise lead to any decrease in non-exercise $\mathrm{EE}$ as there was no significant difference in total daily EE minus the energy cost of exercise. As discussed by Westerterp, in the longer term increased EE due to the physical activity of training does not appear to be compensated by a decrease in leisure-time activity ${ }^{(6)}$. Indeed, training regimens can facilitate greater levels of leisure-time $\mathrm{EE}^{(41)}$.

It is important to note that the present study was conducted in relatively young, lean, sedentary adults who were obliged to exercise to a specific level and knew the EE due to exercise was being monitored. The level of EE when subjects were exercising on the Mex treatment was raised towards that measured in athletes in training; while on the Hex treatment it was elevated towards the upper range of activity level sustainable for prolonged periods ${ }^{(42)}$. Subjects found the exercise regimens arduous, and while they markedly elevated their EE on both the Mex and Hex regimens, we think it unlikely that they would have been as compliant with this protocol if they had not been monitored. Indeed, few subjects continued to exercise at this level once the study was completed. Persuading the general public to increase habitual physical activity to the extent that it has a significant effect on total daily EE and physical fitness remains a distant public health challenge ${ }^{(1,2)}$.

\section{Changes in energy and nutrient intake}

The average compensation of $30 \%$ of the increased energy cost of exercise in the present study is greater than the zero compensation seen in $65 \%$ of short-term studies reviewed by King et al. ${ }^{(14)}$. Evidence from cross-sectional studies suggests a greater correspondence between EE and voluntary EI in habitually active subjects. The present study and our previous studies therefore appear to capture the first stages of a change in intake to match a markedly elevated EE.

What is remarkable about these data is the degree to which subjects tolerated a marked negative EB over periods of $14 \mathrm{~d}$; this requires some consideration.

The study design may have limited the subjects' ability to compensate food intake in the medium term. Examination of the dietary record data showed that the increase in EI was due to a specific increase in fluid intake on going from the Nex treatment to the Hex treatment (values not reported here). The priority given to increasing fluid intake in the short to medium term may have contributed to the lack of EI compensation. Water balance is more tightly defended than is $\mathrm{EB}^{(43,44)}$.

The fixed composition of the available diet restricted food and macronutrient choice. Consumption of high-fat foods has been shown to offset exercise-induced $\mathrm{EE}^{(45,46)}$. The availability of high-fat, and energy-dense, foods provides an opportunity to increase EI without increasing the weight of food consumed $^{(47)}$. In free-living conditions, it is possible that individuals seek out high-fat, energy-dense foods as a reward for exercising $^{(13)}$.

\section{Energy balance}

The average estimates of EB using EI - EE were apparently confirmed by changes in body weight in the men but not the women. It is noteworthy that fairly large and significant changes in fitness only occurred in the women. During weight loss there is a tendency for lean body mass to be preserved if weight is lost during exercise, relative to when weight is lost without exercise ${ }^{(16)}$. In the present study the changes in body weight, which did not exceed $1 \mathrm{~kg}$ in the women and $1.2 \mathrm{~kg}$ in the men, on average, on any of the treatments, were within the measurement error of body composition techniques used to assess change in fat and fat-free mass ${ }^{(48-50)}$. Forbes observes from an analysis of fourteen studies that it is within this range of small change in body weight during exercise regimens that '...individuals whose 
weight did not change usually would be expected to have a modest increase in lean body mass, and thus a comparable loss of body fat in response to exercise ${ }^{,(49)}$. Such changes in body composition in the women in the present study may have confounded estimates of EB from weight per se. The nature of this confound would have been that a negative EB may have occurred that was not attended by a corresponding significant loss of body weight in the women. This is also supported by a recent analysis of several studies by M Elia (personal communication). The reason this effect is likely to have occurred in the women and not the men is that the women were less fit than the men at the outset of the study and so a similar exercise prescription per $\mathrm{kg}$ body weight would have presented a greater training challenge to the women.

\section{Advantages and limitations of the present study}

Specific advantages of the present study were that EI, EE and body weight were independently assessed as precisely as current techniques allow, and that the energy cost of exercise was also quantified, as were subjective indices of motivation to eat and mood. However, the sample size was limited to six lean men and six lean women and the duration of the study was limited to the reasonable time for assessment of EE on each treatment. The small sample size may be a particular issue in relation to the generalisability of the data. Other subjects may behave differently. There are considerable limitations in predicting EE from $\mathrm{HR}^{(30,39)}$ and aerobic power from submaximal fitness tests ${ }^{(40)}$. The use of the relationship between HR and $\mathrm{V}_{\mathrm{O} 2}$ to predict exercise EE would appear justified under the conditions of the present study because subjects were assessed by HRM under the same conditions (i.e. cycling) used to calibrate the HRM.

There are also a number of assumptions inherent in using the relationship between heart rate and $\mathrm{V}_{\mathrm{O} 2}$ to predict $\mathrm{V}_{\mathrm{O} 2 \mathrm{max}}$. These tests assume consistent mechanical efficiency of exercise ${ }^{(39)}$. Mechanical efficiency on a cycle ergometer can show a $4-5 \%$ variation $^{(39)}$. It may take several days for subjects to become maximally efficient on the cycle ergometer, and apparent, small rises in predicted $\mathrm{V}_{\mathrm{O} 2 \max }$ may well reflect a combination of increased fitness and increased mechanical efficiency on the ergometer.

Measurements of isotope dilution spaces were not repeated at the end of each exercise treatment period. Any changes in body composition that may have occurred therefore could not be evaluated.

\section{Conclusions}

The present study captured the first stages of compensation of EI for a marked graded elevation of exercise-induced EE. Compensation was on average weak (about 30\%). Since short-term studies generally suggest no compensation and cross-sectional studies suggest greater intakes in active $v$. sedentary individuals, we conclude that EI only begins to track EE over the course of 1-2 weeks in lean men and women. The increased fluid intake in response to exercise suggests to us that part of the apparent delay in compensation of EI for elevations of EE could result from the necessity to defend water balance in preference to EB. Some subjects appeared to be less compliant with the ad libitum diet than were others. When these five subjects were excluded, EI increased by about $56 \%$ of the energy cost of exercise across treatments. The extent of compensation remained highly variable. Studies are needed with larger numbers of subjects to fully elucidate the basis for inter-individual variability in compensation of EI for exercise-induced energy deficits.

\section{Acknowledgements}

We gratefully acknowledge the expertise and technical assistance from Mr Eric Milne and Mrs Paula Redman.

The authors declare that no conflict of interest existed.

The present study was supported by the Scottish Executive Environment Rural Affairs Department and Biotechnology and Biological Science Research Council grant F02501.

S. W. wrote the manuscript. A. M. J. conducted the study in the women and analysed the data, and D. A. H. the men. P. R. carried out the doubly labelled water analysis. G. W. H. performed the statistical analysis. R. J. S. was the project leader and was involved in the study design. All authors contributed to the interpretation of results, writing of the manuscript, and read and approved the final version.

\section{References}

1. Anonymous (1992) Allied Dunbar National Fitness Survey: Main Findings. London: Sports Council and Health Education Authority.

2. Department of Health (1995) The Health of the Nation. Reversing the Increasing Problem of Obesity in England. A report from the Nutrition and Physical Activity Task Forces. London: Department of Health.

3. Garrow JS \& Summerbell CD (1995) Metaanalysis - effect of exercise, with or without dieting, on the body composition of overweight subjects. Eur J Clin Nutr 49, 1-10.

4. Sum CF, Wang KW, Choo DCA, Tan CE, Fok ACK \& Tan EH (1994) The effect of a 5-month supervised program of physical activity on anthropometric indexes, fat-free mass, and resting energy expenditure in obese male military recruits. Metabolism 43, $1148-1152$.

5. Van Etten LMLA, Westerterp KR, Verstappen FTJ, Boon BJB \& Saris WHM (1997) Effect of an 18-wk weight-training program on energy expenditure and physical activity. $J$ Appl Physiol 82, 298-304.

6. Westerterp KR (1998) Alterations in energy balance with exercise. Am J Clin Nutr 68, 970S-974S.

7. van Baak MA (1999) Physical activity and energy balance. Public Health Nutr 2, Suppl. 1, 335-339.

8. Bovens AM, Vanbaak MA, Vrencken JG, Wijnen JA, Saris WH \& Verstappen FT (1993) Physical activity, fitness, and selected risk factors for CHD in active men and women. Med Sci Sports Exerc 25, 572-576.

9. McGowan CR, Epstein LH, Kupfer DJ, Bulik CM \& Robertson RJ (1986) The effect of exercise on nonrestricted caloric intake in male joggers. Appetite 7, 97-105.

10. Barr SI \& Costill DL (1992) Effect of increased training volume on nutrient intake of male collegiate swimmers. Int J Sports Med 13, 47-51.

11. Schoeller DA, Shay K \& Kushner RF (1997) How much physical activity is needed to minimize weight gain in previously obese women? Am J Clin Nutr 66, 551-556.

12. Saris WHM (1993) The role of exercise in the dietary treatment of obesity. Int J Obes 17, S17-S21. 
13. Blundell JE \& King NA (1999) Physical activity and regulation of food intake: current evidence. Med Sci Sports Exerc 31, S573-S583.

14. King NA, Tremblay A \& Blundell JE (1997) Effects of exercise on appetite control: implications for energy balance. Med Sci Sports Exerc 29, 1076-1089.

15. Blundell JE, Stubbs RJ, Hughes DA, Whybrow S \& King NA (2003) Cross talk between physical activity and appetite control: does physical activity stimulate appetite? Proc Nutr Soc 62 , 651-661.

16. Ballor DL \& Poehlman ET (1994) Exercise-training enhances fat-free mass preservation during diet-induced weight loss - a meta-analytical finding. Int $J$ Obes 18, 35-40.

17. Woo R \& Pi-Sunyer FX (1985) Effect of increased physical activity on voluntary intake in lean women. Metabolism 34, 836-841.

18. Woo R, Garrow JS \& Pisunyer FX (1982) Effect of exercise on spontaneous calorie intake in obesity. Am J Clin Nutr 36, $470-477$.

19. Woo R, Garrow JS \& Pisunyer FX (1982) Voluntary food intake during prolonged exercise in obese women. Am J Clin Nutr 36, $478-484$.

20. King NA, Snell L, Smith RD \& Blundell JE (1996) Effects of short-term exercise on appetite responses in unrestrained females. Eur J Clin Nutr 50, 663-667.

21. King NA, Lluch A, Stubbs RJ \& Blundell JE (1997) High dose exercise does not increase hunger or energy intake in free living males. Eur J Clin Nutr 51, 478-483.

22. Imbeault P, Saint-Pierre S, Almeras N \& Tremblay A (1997) Acute effects of exercise on energy intake and feeding behaviour. Br J Nutr 77, 511-521.

23. Dionne I, Johnson M, White MD, StPierre S \& Tremblay A (1997) Acute effect of exercise and low-fat diet on energy balance in heavy men. Int J Obes 21, 413-416.

24. Yoshioka M, Doucet E, St-Pierre S, Almeras N, Richard D, Labrie A, Despres JP, Bouchard C \& Tremblay A (2001) Impact of high-intensity exercise on energy expenditure, lipid oxidation and body fatness. Int $J$ Obes 25, 332-339.

25. Kempen KPG, Saris WHM \& Westerterp KR (1995) Energybalance during an 8-wk energy-restricted diet with and without exercise in obese women. Am J Clin Nutr 62, 722-729.

26. Stubbs RJ, Sepp A, Hughes DA, Johnstone AM, King N, Horgan G \& Blundell JE (2002) The effect of graded intake and balance levels of exercise on energy in free-living women. Int J Obes 26, 866-869.

27. Stubbs RJ, Sepp A, Hughes DA, Johnstone AM, Horgan GW, King N \& Blundell J (2002) The effect of graded levels of exercise on energy intake and balance in free-living men, consuming their normal diet. Eur J Clin Nutr 56, 129-140.

28. Johnstone AM, Shannon EL, Whybrow S, Reid CA \& Stubbs RJ (2000) Altering the temporal distribution of energy intake with isoenergetically dense foods given as snacks does not affect total daily energy intake in normal weight men. Br J Nutr 83, 7-14.

29. Stubbs RJ, Johnstone AM, Mazlan N, Mbaiwa SE \& Ferris S (2001) Effect of altering the variety of sensorially distinct foods, of the same macronutrient content, on food intake and body weight in men. Eur J Clin Nutr 55, 19-28.

30. Ceesay SM, Prentice AM, Day KC, Murgatroyd PR, Goldberg GR, Scott W \& Spurr GB (1989) The use of heart rate monitoring in the estimation of energy expenditure: a validation study using indirect whole-body calorimetry. Br J Nutr 61, 175-186.

31. Stunkard AJ \& Messick S (1985) The three-factor eating questionnaire to measure dietary restraint, disinhibition and hunger. J Psychosom Res 29, 71-83.

32. van Strien T, Frijters J, Bergers G \& Defares P (1986) The Dutch eating behaviour questionnaire (DEBQ) for assessment of restrained, emotional and external eating behaviour. Int $J$ Eat Disord 5, 295-315.

33. Elia M \& Livesey G (1992) Energy expenditure and fuel selection in biological systems: the theory and practice of calculations based on indirect calorimetry and tracer methods. World Rev Nutr Diet 70, 68-131.

34. Durnin JVGA \& Womersley J (1974) Body fat assessed from total body density and its estimation from skinfold thickness: measurements on 481 men and women aged from 16 to 72 years. Br J Nutr 32, 77-97.

35. Siri WE (1961) Body composition from fluid spaces and density: analysis of methods. In Techniques for Measuring Body Composition, pp. 223-244 [J Brozek and A Henschel, editors]. Washington, DC: National Academy of Science.

36. Holland B, Welch AA, Unwin ID, Buss DH, Paul AA \& Southgate DAT (1991) McCance and Widdowson's The Composition of Foods, 5th ed. Cambridge: The Royal Society of Chemistry and Ministry of Agriculture, Fisheries and Food.

37. Coward WA \& Cole TJ (1991) The doubly labelled water method for the measurement of energy expenditure in humans: risks and benefits. In New Techniques in Nutritional Research, pp. 139-176 [RG Whitehead and A Prentice, editors]. London: Academic Press.

38. Coward WA (1989) Calculation of pool sizes and flux rates. In The Doubly Labelled Water Method for Measuring Energy Expenditure: Technical Recommendations for Use in Humans. A Consensus Report by the IDECG Working Group, pp. 48-68 [AM Prentice, editor]. Vienna: International Atomic Energy Agency.

39. Murgatroyd PR, Shetty PS \& Prentice1 AM (1993) Techniques for the measurement of human energy expenditure: a practical guide. Int J Obes 17, 549-568.

40. Shephard RJ (1984) Tests of maximum oxygen intake - a critical review. Sports Med 1, 99-124.

41. Blaak EE, Westerterp KR, Baror O, Wouters LJM \& Saris WHM (1992) Total energy expenditure and spontaneous activity in relation to training in obese boys. Am J Clin Nutr 55, $777-782$.

42. Black AE, Coward WA, Cole TJ \& Prentice AM (1996) Human energy expenditure in affluent societies: an analysis of 574 doubly-labelled water measurements. Eur J Clin Nutr 50, $72-92$.

43. Stricker EM \& Verbalis JG (1999) Fluid intake and homeostasis. In Fundamental Neuroscience, pp. 1091-1109 [EMJ Zigmond, F Bloom, SC Landis, JL Roberts and LR Squire, editors]. San Diego, CA: Academic Press.

44. Stricker EM (2000) Specific appetites and homeostatic systems. In Neural and Metabolic Control of Macronutrient Intake, pp. 856-872 [H-R Berthoud and R Seeley, editors]. Boca Raton, FL: CRC Press.

45. Murgatroyd PR, Goldberg GR, Leahy FE, Gilsenan MB \& Prentice AM (1999) Effects of inactivity and diet composition on human energy balance. Int J Obes 23, 1269-1275.

46. Tremblay A, Almeras N, Boer J, Kranenbarg EK \& Despres JP (1994) Diet composition and postexercise energy balance. Am J Clin Nutr 59, 975-979.

47. Blundell JE \& Macdiarmid JI (1997) Passive overconsumption. Fat intake and short-term energy balance. Ann $N$ Y Acad Sci 827, 392-407.

48. Forbes GB (1987) Lean body mass-body fat interrelationships in humans. Nutr Rev 45, 225-231.

49. Forbes GB (1998) Exercise and body composition revisited: the effect of body weight change. Appl Radiat Isot 49 , $575-575$.

50. Forbes GB (1998) Longitudinal changes in adult body composition: influence of body weight. Appl Radiat Isot 49, 571-573. 